\title{
Synthetic Peptides Affect the Expression of Gdnf and Gdnf Receptors in Rats with 6-0HDA-Induced PD-Like Parkinsonism
}

\author{
Elena V. Filatova, Maria I. Shadrina, Timur A. Kolomin, Ludmila A. Andreeva, Nikolay F. Myasoedov, \\ Petr A. Slominsky
}

Institute of Molecular Genetics, Russian Academy of Sciences, Moscow, Russia

Email: FilatovaEV@img.ras.ru

How to cite this paper: Filatova, E.V., Shadrina, M.I., Kolomin, T.A., Andreeva, L.A., Myasoedov, N.F. and Slominsky, PA. (2016) Synthetic Peptides Affect the Expression of Gdnf and Gdnf Receptors in Rats with 6-OHDA-Induced PD-Like Parkinsonism. World Journal of Neuroscience, 6 , 243-259.

http://dx.doi.org/10.4236/wjns.2016.64030

Received: August 23, 2016

Accepted: October 16, 2016

Published: October 19, 2016

Copyright $\odot 2016$ by authors and Scientific Research Publishing Inc. This work is licensed under the Creative Commons Attribution International License (CC BY 4.0).

http://creativecommons.org/licenses/by/4.0/

\section{(c) (i) Open Access}

\begin{abstract}
Parkinson's disease (PD) is the second most common severe neurodegenerative disorder. It is characterized by progressive degeneration of dopaminergic neurons in the substantia nigra pars compacta. Unfortunately, PD remains incurable. Therapy based on regulatory peptides, particularly neuroprotective peptides, which can sustain or activate neuron plasticity to enable their survival and function in difficult environments and after violated homeostasis, is a promising approach to cure PD. Some studies show that the synthetic analogs of natural peptides may be used as an etiological or at least a complementary therapy in PD. Therefore, in the present pilot study, we investigated the effects of the synthetic peptides Semax and dopamine neuron stimulating peptide (DNSP-5), and a new synthetic Semax-DNSP-5 hybrid peptide (SD) on the functioning of brain neurons. An analysis of the levels of dopamine (DA), noradrenaline (NA), 5-hydroxytriptamine (5-HT), an expression analysis of Gdnt and Gdnf receptor genes Gfra1, Gfra2, Gfra3, Gfra4, and Gfral in various regions of the brain of rats with 6-OHDA-induced PD-like parkinsonism, and a study of the motor activity of the rats in an "open field" test showed that DNSP-5 and SD elevated the level of DA in the nonlesioned striatum. DNSP-5 also increased the expression of Gfral and Gfra2 in the nonlesioned striatum and lesioned substantia nigra (SN) which suggested that DNSP-5 had compensatory and neuroprotective properties. SD demonstrated similar, albeit less pronounced effects to DNSP-5 on DA metabolism and gene expression. Of the peptides studied, only SD tended to increase the horizontal and vertical activity of rats. In conclusion, these findings suggest that DNSP-5 and SD have potential neuroprotective properties and may stimulate the surviving DA neurons.
\end{abstract}




\section{Keywords}

6-OHDA, Parkinson's Disease, Semax, DNSP-5, Gene Expression

\section{Introduction}

Parkinson's disease (PD) is the second most common severe neurodegenerative disorder. It is characterized by progressive degeneration of dopaminergic neurons in the substantia nigra pars compacta (SNpc). PD first manifests clinically after the death of $60 \%-80 \%$ dopaminergic neurons in the SNpc [1] [2], and the first clinical signs appear approximately 5 years after the beginning of the disease [3]. Unfortunately, PD remains incurable, and all treatment of PD is symptomatic, is unable to stop the progression of the disease, and causes unfavorable side effects [4]-[6]. Drugs in current use were designed to elevate levels of dopamine (DA) by increasing synthesis of DA and/or decreasing its metabolism [6] [7], thereby restoring motor deficits associated with nigrostriatal dysfunction [6]. However, these drugs fail to support damaged DA neurons or increase their survival. Therefore, neuroprotection and neurorestoration may be a solution to the problems of conventional therapy for PD. The aim of the neurorestoration therapy is to change the pathophysiological environment towards restoration of the DA phenotype [8].

Therapy based on regulatory peptides, particularly neuroprotective peptides, which can sustain or activate neuron plasticity to enable their survival and function in difficult environments and after violated homeostasis, is a promising approach. Glial cell linederived neurotrophic factor (GDNF) has been considered as the most promising neurotrophic factor [9]. GDNF belongs to the GDNF family ligands which consist of GDNF, neurturin, artemin, and persephin, and they form a distant group in the TGF- $\beta$ superfamily [10]. GDNF family members function as homodimers and signals through a transmembrane receptor tyrosine kinase (RET) by first binding to their cognate GDNF family receptor $\alpha$ (GFRA) [10]. Although GDNF is not specific for DA neurons, it has been shown to promote the survival of several other neuronal populations, including motoneurons, noradrenergic, serotonergic, enteric, peripheral sensory and autonomic neurons [8]. GDNF demonstrates robust restorative and protective effects on DA neurons [11]-[14]. However, the clinical utility of GDNF has been compromised by a failed phase II trial, potential toxicity [15], limited diffusion of GDNF to target areas [16] [17], and difficult delivery [18] [19], which may be overcome by a promising approach of intranasal delivery [20].

Another promising group of peptides is adrenocorticotropic hormone (ACTH) and its fragments, which represent one of the most actively studied classes of endogenous regulatory peptides and display a broad range of extrahormonal activities [21]. Numerous studies have shown nootropic effects of ACTH and its fragments [22]-[27]. However, most importantly, neurotrophic effects of ACTH and its fragments are also discovered. ACTH exerts a trophic action on cultured neurons [28]. ACTH fragments 
elicit the maturation of serotonergic neurons [29] and induce peripheral nerve regeneration [30] [31]. The marked nootropic, neuroprotective, and neurotrophic effects of ACTH and its fragments have transformed them into the most promising candidates for the prevention and treatment of pathologies of the central nervous system.

Synthetic analogs can be developed on the basis of natural regulatory peptides such as ACTH [21] and GDNF [4] [32]. Modifications can be made to increase the stability of the peptides [21].

A small synthetic peptide, dopamine neuron stimulating peptide (DNSP-5), structurally based on the GDNF sequence, shows neuroprotective and neurotrophic-like properties in vitro and in vivo [4] [32]. The synthetic analog of an ACTH 4-10 fragment (ACTH 4-10), Semax, is a powerful neuroprotective agent that is particularly effective as a therapy for stroke. It exhibits distinct neuroprotective and nootropic properties and is the basis of a number of drugs used in clinical practice to treat CNS diseases (including ischemic brain stroke, dyscirculatory encephalopathy, and optic nerve atrophy) and enhance adaptability in healthy persons under extreme conditions [21]. These studies suggest that synthetic peptides may be used as an etiological or at least a complementary therapy in PD.

Therefore, in the present pilot study, we investigated the effects of synthetic peptides on the functioning of brain neurons. We chose Semax, DNSP-5, and a Semax-DNSP-5 hybrid peptide (SD) for this purpose. We conducted an analysis of DA, noradrenaline (NA), 5-hydroxytriptamine (5-HT), and an expression analysis of Gdnf and Gdnf receptor genes Gfra1, Gfra2, Gfra3, Gfra4, and Gfral, because the genes were involved in survival and differentiation of dopaminergic neurons in various regions of the brain of rats with the 6-OHDA-induced PD-like parkinsonism, along with a study of the motor activity of the rats.

\section{Materials and Methods}

\subsection{Peptides}

We studied gene expression changes in various regions of rat brains after course administration of three synthetic peptides: Semax (neuroprotective and nootropic synthetic analog of the 4 - 10 fragment of adrenocorticotropic hormone (ACTH): MEHFPGP); DNSP-5 (synthetic analog of the fragment of glial cell derived neurotrophic factor (GDNF): FPLPA); and SD (a hybrid peptide of Semax and DNSP-5: MEHFPLPA). The peptides were synthesized at the Institute of Molecular Genetics, Russian Academy of Sciences.

\subsection{Animals}

Male Wistar rats (mean weight, $250 \pm 30 \mathrm{~g}$ ) were used in this study. The rats were kept in a vivarium with an environmental temperature of $22^{\circ} \mathrm{C}$, a 12-h light/dark cycle (7:00 am onset) and free access to water and food. Procedures were conducted in strict accordance with IACUC guidelines. All efforts were made to minimize animal suffering and reduce the number of animals used. This study was approved by The Ethics Com- 
mittee of the Institute of Molecular Genetics, Russian Academy of Sciences.

\subsection{Striatal Lesion}

The DA neuron-selective neurotoxin, 6-OHDA hydrobromide, was administered in $0.9 \%$ saline containing $0.05 \% \mathrm{~L}$-ascorbic acid (vehicle) using a Hamilton syringe fitted with a 27 -gauge needle to obtain a unilateral nigrostriatal lesion. The rats were anesthetized with $50 \mathrm{mg} / \mathrm{kg}$ of ketamine and $5 \mathrm{mg} / \mathrm{kg}$ of benzodiazepine intraperitoneally. A burr hole was made in the skull using a dental drill, and after careful piercing of the dura mater, the needle of the Hamilton syringe was inserted vertically into both hemispheres in turn according to the stereotaxic coordinates: $-4.8 \mathrm{~mm}$ posterior and 2.0 $\mathrm{mm}$ lateral to bregma, $-7.0 \mathrm{~mm}$ with reference to the dura. 6-OHDA $(10 \mu \mathrm{g})$ in $2 \mu \mathrm{L}$ of the vehicle was infused at a rate of $0.4 \mu \mathrm{L} / \mathrm{min}$ for a total infusion time of $7.5 \mathrm{~min}$ into the right hemisphere. The left hemisphere was infused with vehicle. Sham-operated rats were infused with the equivalent amount of vehicle into both hemispheres. After infusions, the needle was left in place for $1.5 \mathrm{~min}$ and then slowly retracted.

\subsection{Study Design}

The rats were divided into five groups as follows: three experimental (11 rats in each group that received Semax, DNSP-5, or SD) groups; a control group (10 rats that received water); and a group with 6 sham-operated rats.

Administration of the peptides started the day after surgery. Three experimental groups of rats received daily Semax $(300 \mu \mathrm{g} / \mathrm{kg})$, DNSP-5 $(150 \mu \mathrm{g} / \mathrm{kg})$, or SD $(150 \mu \mathrm{g} /$ $\mathrm{kg}$ ) intranasally. Animals were sacrificed 5 weeks after surgery. Immediately after they were humanely killed, their brains were dissected, and the various regions were immediately frozen in liquid nitrogen and stored at $-70^{\circ} \mathrm{C}$.

\subsection{Behavioral Study}

Testing of the motor activity of rats was conducted using an "open field" test method for $3 \mathrm{~min}$. The number of crossed squares (horizontal activity) and the number of stands on hind legs (vertical activity) were taken into account. Each rat was tested three times during the study: 1 week before surgery, 1 and 4 weeks after surgery. The behavior of the rats was recorded using a web camera and the basic software package for planning and optimization of the experiment RealTimer (OpenScience).

\subsection{RNA Isolation}

Total RNA was isolated from a $10 \mathrm{mg}$ sample of tissue from each of the following regions of the rat brains: right and left frontal cortex (FR and FL); right and left olfactory bulbs (OR and OL); right and left striatum (SR and SL); right and left hippocampus (HR and HL); and right and left substantia nigra (SNR and SNL). Total RNA isolation from the rat brains for expression analysis of individual genes was performed for each individual animal. Total RNA isolation was conducted using an RNAeasy Mini Kit (Qiagen) according to the manufacturer's recommendations. The concentration of total 
RNA isolated was measured using a Quant-iT RNA BR Assay Kit and a Qubit fluorimeter (Invitrogen). RNA quality was monitored using an Experion automated electrophoresis system (Bio-Rad Laboratories). The RNA quality index was higher than 8.5 in all samples.

\subsection{RT-qPCR}

Gene expression analysis was conducted using a reverse transcription (RT) reaction and real-time quantitative PCR (qPCR) with TaqMan probes. Single-stranded DNA was synthesized using $500 \mathrm{ng}$ of total RNA, $100 \mathrm{ng}$ of Escherichia coli tRNA as a carrier [33], specific primers, and the RevertAid H Minus First Strand cDNA Synthesis Kit (Thermo Fischer Scientific) according to the manufacturer's recommendations. Each $\mathrm{RT}$ reaction was run in triplicate. The sequences of gene-specific primers and probes are presented as follows:

Gdnf-f: 5'-CGCGCTGACCAGTG;

Gdnf-r: 5'ATGGTGGCTTGAATAAAATC;

Gdnf-p: 5'FAM-CGTCATCAAACTGGTCAGGATAATCTT-BHQ1;

Gfra1-f: 5'-CCTAGCCACTCTGTACTTC;

Gfra1-r: 5'-CAGCTCTGTTCCTTCAGG;

Gfra1-p: 5'-FAM-ACAGTCCAGACGGTCTCCAC-BHQ1;

Gfra2-f: 5'-CTCCTACCGGACAATCAC;

Gfra2-r: 5'-GTTGGAGTCCACATAGTTG;

Gfra2-p: 5'-FAM-CAATCATGCCAGCATAGGAGCC-BHQ1;

Gfra3-f: 5'-CCTGTCTGGACATTTATTG;

Gfra3-r: 5'-GGTCACTGTGTCTTCATA;

Gfra3-p: 5'-FAM-CCGAAGCCTTGGTGACTACGA-BHQ1;

Gfra4-f: 5'-CACCTTCCTGCCTGAAGCC;

Gfra4-r: 5'-TCCTCCGGACAGCCGTC;

Gfra4-p: 5'-FAM-GCCGGTGCCGGCCCCGTC-BHQ1;

Gfral-f: 5'-GCTTGACTGATACAGATG;

Gfral-r: 5'-GGCAATGGATTATTTATCTTG;

Gfral-p: 5'-FAM-TCAATGGAAGACGCCTGCCT-BHQ1;

Tfrc-F: 5'-GGCAGACCTCAAAACACTGTTG-3';

Tfrc-R: 5'-CAGCCTCACGAGGAGTATATGTATTC-3';

Tfrc-P: 5'-VIC-TTCACTGACATCATCAAGCAGCTGAGCC-BHQ2-3';

Tspo-F: 5'-AGGCTGTGGATCTTTCCAGAAC-3';

Tspo-R: 5'-GGCTGGGCACCAGAGTGA-3';

Tspo-P: 5'- VIC-CAATCACTATGTCTCAATCCTGGGTACCCG-BHQ2-3'.

qPCR was performed using cDNA, which was diluted 50 times in an aqueous solution of E. coli tRNA to introduce $100 \mathrm{ng}$ of the carrier to each reaction tube [33], PCR reagents (Syntol), and a StepOnePlus System (Applied Biosystems). Thermal cycling was performed as follows: 1) $600 \mathrm{~s}$ at $95^{\circ} \mathrm{C}$, and 2) 45 cycles: $5 \mathrm{~s}$ at $95^{\circ} \mathrm{C}$ followed by $10 \mathrm{~s}$ at $60^{\circ} \mathrm{C}$. qPCR was replicated three times for each cDNA. Tspo and Tfrc transcripts 
were used as references to normalize gene expression data.

\subsection{Analysis of Neurotransmitters}

We analyzed levels of DA, NA, and 5-HT in the left and right striatum of all rats. To validate the 6-OHDA-induced lesion, the content of monoamines in these samples (nmol/g of tissue) was measured using HPLC with electrochemical detection, as described elsewhere [34] [35].

\subsection{Statistical Analysis}

The sequences of the primers and probes for expression analysis of the chosen genes Gdnf, Gfra1, Gfra2, Gfra3, Gfra4, and Gfral, and reference genes Tspo and Tfrc were designed using Beacon Designer 7.0 software (Premier Biosoft International).

Relative levels of the transcripts in the experimental groups were calculated as $\mathrm{R}=$ $2-\Delta \Delta \mathrm{Cp}$ [36]. The levels of the transcripts studied in the control group (rats that received water) were set as 1 . Data were analyzed with a nonparametric Mann-Whitney U test using Statistica for Windows 8.0 (StatSoft, 2007) and Microsoft Excel 2010.

\section{Results}

In the present study, we assessed the success of the 6-OHDA lesion to induce a PD-like phenotype using the following inclusion criteria: sham-operated rats did not reduce their motor activity, and animals with a 6-OHDA lesion significantly reduced their horizontal and vertical activity 1 week after the surgery. Of the peptides studied, only SD affected the horizontal and vertical activity of rats (Table 1). By the fourth week after surgery, the motor activity of the rats that received SD did not remain at the same level, as they did 1 week after the lesion, but increased, albeit insignificantly. Neither DNSP-5 nor Semax affected the behavior of the rats.

\subsection{Biochemistry}

We analyzed the levels of DA, NA, and 5-HT in left and right striatum in all rats to validate the damage to the DA neurons by the toxin in our model of PD, and to reveal possible changes of levels of the monoamines after administration of the peptides. The 6-OHDA lesion was considered successful when concentrations of the substances in left and right striatum were equal in the group of sham-operated animals, and the concen-

Table 1. Horizontal and vertical activity of the rats in the "open field" test.

\begin{tabular}{ccccccc}
\hline & h0 & h1 & h4 & v0 & v1 & v4 \\
\hline $\mathrm{H}_{2} \mathrm{O}$ & $63 \pm 22.58$ & $32 \pm 21.35$ & $18 \pm 17.55$ & $14 \pm 6.83$ & $4 \pm 4.06$ & $2 \pm 2.67$ \\
Semax & $66.5 \pm 18.46$ & $27 \pm 15.89$ & $10 \pm 10.01$ & $14 \pm 5.43$ & $5 \pm 3.44$ & $1 \pm 1.36$ \\
DNSP-5 & $69.5 \pm 13.15$ & $31 \pm 19.1$ & $21 \pm 14.17$ & $12.5 \pm 7.82$ & $6 \pm 4$ & $1 \pm 0.77$ \\
SD & $66.5 \pm 13.24$ & $21 \pm 16.93$ & $32 \pm 19.72$ & $16 \pm 6.4$ & $2 \pm 4.38$ & $3 \pm 4.63$ \\
\hline
\end{tabular}

Data are represented as median \pm standard deviation. $\mathrm{h} 0$ and v0-horizontal and vertical activity before the surgery respectively, h1 and v1-horizontal and vertical activity 1 week after the surgery respectively, $\mathrm{h} 4$ and v4-horizontal and vertical activity 4 weeks after the surgery respectively. 
tration of DA was significantly lower in the right striatum of the animals from the 6-OHDA-treated groups, which indicates the effectiveness of the procedure we used in this study (Table 2 and Table 3). All rats met the inclusion criteria. As it can be seen in Table 2, the surgery did not affect the levels of DA, NA, or 5-HT in the striatum of sham-operated rats.

Our results demonstrate that the peptides Semax, DNSP-5, and SD affect the levels of monoamines in rats with 6-OHDA-induced PD-like parkinsonism. We found a significant elevation of the DA level in the left striatum of rats after the administration of DNSP-5 compared with the left striatum of the control (rats that received water) (Table 3). Moreover, SD also demonstrated a tendency to increase the level of DA in the left striatum compared with the control. Unfortunately, this difference was not significant. Surprisingly, the level of 5-HT was significantly higher in the right striatum of rats that received Semax than in the right striatum of rats from the control group (Table 3).

\section{2. qPCR}

In the present study, we investigated the effects of synthetic peptides DNSP-5, Semax, and SD on the expression of Gdnf and Gdnf receptor genes Gfra1, Gfra2, Gfra3, Gfra4, and Gfral in various regions of the rat brain in the 6-OHDA-induced model of PD. Analysis of qPCR data showed that the values of quantification cycles (Cq) of Gfra3 were higher than 35 , which indicates the low representation of mRNA in the tissues examined. Therefore, this gene was excluded from further analysis.

In the present study, 6-OHDA administration did not affect the expression of most of the genes studied (Table 4). The relative levels of most of the mRNA of the genes in

Table 2. Levels of DA, NA, and 5-HT in striatum of sham-operated rats.

\begin{tabular}{cccc}
\hline & DA & NA & 5-HT \\
\hline SO L & $84.97 \pm 64.67$ & $8.23 \pm 9.86$ & $16.49 \pm 3.08$ \\
SO R & $104.68 \pm 70.86$ & $4.47 \pm 7.92$ & $11.72 \pm 3.30$ \\
\hline
\end{tabular}

Data are shown as nmol/g of tissue and represented as median \pm standard deviation. SO R and SO L-right and left striatum of sham-operated rats respectively.

Table 3. Levels of DA, NA, and 5-HT in striatum of rats from the control and experimental groups.

\begin{tabular}{cccc}
\hline & DA & NA & 5-HT \\
\hline H2O L & $95.80 \pm 56.67 !$ & $8.39 \pm 10.88$ & $16.58 \pm 6.21$ \\
H2O R & $24.45 \pm 33.48 !$ & $3.39 \pm 13.69$ & $14.38 \pm 5.09$ \\
Semax L & $121.78 \pm 83.06 !$ & $6.53 \pm 6.80$ & $23.31 \pm 5.81$ \\
Semax R & $24.24 \pm 64.41 !$ & $5.30 \pm 6.51$ & $18.58 \pm 5.92^{\star}$ \\
DNSP-5 L & $211.18 \pm 68.60^{* !}$ & $6.78 \pm 7.85$ & $19.81 \pm 5.18$ \\
DNSP-5 R & $15.79 \pm 59.26 !$ & $2.02 \pm 2.87$ & $13.99 \pm 2.91$ \\
SD L & $177.70 \pm 89.34 !$ & $5.35 \pm 7.65 !$ & $14.74 \pm 4.88$ \\
SD R & $19.30 \pm 50.27 !$ & $3.33 \pm 2.47 !$ & $16.46 \pm 5.76$ \\
\hline
\end{tabular}

Data are shown as nmol/g of tissue and represented as median \pm standard deviation. ${ }^{*}$-data in experimental group differ from data in the group of animals that received water $(\mathrm{p}<0.05)$, ! - data differ between left and right striatum $\mathrm{p}<0.05$. 
Table 4. Relative levels of Gdnf and Gdnf receptor genes in various regions of the rat brain after administration of water.

\begin{tabular}{cccccc}
\hline & Gdnf & Gfra1 & Gfra2 & Gfra4 & Gfral \\
\hline FR & 0.98 & 1.02 & 1.27 & 1.21 & 1.22 \\
FL & 0.7 & 1.38 & 0.83 & 1.09 & 1.02 \\
HR & 1.34 & 1.11 & 2.32 & 1.07 & 1.92 \\
HL & 0.44 & 0.81 & 0.75 & 1.08 & 2.1 \\
OR & 0.85 & 1.13 & 1.26 & 1.03 & 2.38 \\
OL & $0.31^{*}$ & 0.66 & 1.06 & 1.50 & 1.14 \\
SNR & 0.53 & 1.68 & 0.51 & 1.47 & 1.12 \\
SNL & 0.66 & 0.74 & 1.02 & 0.97 & 1.38 \\
SR & 1.21 & $0.49^{*}$ & 0.49 & 1.12 & 2.05 \\
SL & 1.81 & 2.91 & 1.29 & 0.89 & 2.42 \\
\hline
\end{tabular}

Data are shown as median; ${ }^{*}$-data in the control group differ from data in the group of sham-operated rats $(\mathrm{p}<$ 0.05). FR -right frontal cortex, FL-left frontal cortex, HR-right hippocampus, HL-left hippocampus, OR—right olfactory bulb, OL—left olfactory bulb, SNR—right substantia nigra, SNL—left substantia nigra, SR—right striatum, SL-left striatum. The levels of the transcripts studied in the group of sham-operated rats were set as 1.

the control group (animals that received water) did not differ from those in the group of sham-operated rats.

Because the main aim of our study was to investigate the effects of the peptides, the control group for the expression analysis consisted of the rats that received water.

In general, DNSP-5 affected the expression of the genes studied in the largest number of tissues (Table 5), while Semax changed the expression of the genes in the smallest number of tissues (Table 6). We note that the expression of Gfra4 was significantly decreased only in the HR after the administration of DNSP-5 (Table 5). Gfra2 expression was altered the most, but not in the OR, OL, SR, or HL (Tables 5-7).

DNSP-5 greatly affected the expression of the genes studied (Table 5). Interestingly, the expression of Gfral and Gfra2, which encode receptors to Gdnf, was increased more than 2-fold in the SNR compared with the controls, and the expression of Gdnf was decreased more than 2-fold in this region. By contrast, the expression of Gfra2 was decreased in the SNL. The expression of Gfra2 was increased in the SL, and the relative levels of Gfral transcript were elevated in the SL and SR compared with the controls. The Gdnf mRNA levels were higher in the olfactory bulbs of animals who received DNSP-5 that in the control rats. Moreover, the expression of Gfra2 and Gfra4 was decreased in the HR under the influence of DNSP-5 (Table 5).

Semax increased Gdnf expression 3-fold in the HR compared with the control rats that received water. The expression of Gfral increased more than 1.5-fold in the SNR, and the expression of Gfra2 decreased more than 2-fold in the FR after administration of Semax (Table 6).

$\mathrm{SD}$ also affected the expression of the genes studied. The expression of $G d n f$ was only changed in the right hemisphere of the rat brain. Its relative levels were higher in the HR and SR and lower in the OR and SNR compared with the controls. By contrast, the expression of Gfral and Gfra2 showed a tendency to be elevated in the SNR after ad- 
Table 5. Relative levels of Gdnf and Gdnf receptor genes in various regions of the rat brain after DNSP-5 administration.

\begin{tabular}{cccccc}
\hline & Gdnf & Gfral & Gfra2 & Gfra4 & Gfral \\
\hline FR & 0.77 & $0.63^{*}$ & $0.49^{*}$ & 0.81 & 1.34 \\
FL & 0.73 & 1.00 & 1.24 & 0.64 & 2.80 \\
HR & 2.70 & 0.85 & $0.39^{*}$ & $0.56^{*}$ & 0.75 \\
HL & 0.95 & 0.91 & 0.67 & 0.72 & 1.88 \\
OR & $0.34^{*}$ & 0.88 & 0.82 & 0.68 & 7.41 \\
OL & $0.59^{*}$ & 1.06 & 1.29 & 1.12 & 1.12 \\
SNR & $0.35^{*}$ & $2.21^{*}$ & $1.89^{*}$ & 2.01 & 0.60 \\
SNL & 0.88 & 1.38 & $0.44^{*}$ & 1.83 & 1.27 \\
SR & 1.88 & 1.10 & 1.03 & 1.12 & $4.99^{*}$ \\
SL & 1.14 & 2.74 & $2.98^{*}$ & 1.10 & $3.01^{*}$ \\
\hline
\end{tabular}

Data are shown as median; FR-right frontal cortex, FL-left frontal cortex, HR-right hippocampus, HL-left hippocampus, OR - right olfactory bulb, OL-left olfactory bulb, SNR - right substantia nigra, SNL-left substantia nigra, SR-right striatum, SL-left striatum. *-data in the experimental group differ from data in the group of animals that received water $(\mathrm{p}<0.05)$. The levels of the transcripts studied in the control group (rats that received water) were set as 1 .

Table 6. Relative levels of $G d n f$ and Gdnf receptor genes in various regions of the rat brain after Semax administration.

\begin{tabular}{cccccc}
\hline & Gdnf & Gfral & Gfra2 & Gfra4 & Gfral \\
\hline FR & 0.99 & 0.75 & $0.48^{*}$ & 1.46 & 0.91 \\
FL & 1.11 & 0.98 & 0.88 & $1.50^{*}$ & 1.34 \\
HR & $3.02^{*}$ & 0.84 & 0.68 & 0.85 & 0.68 \\
HL & 0.81 & 1.20 & 1.14 & 0.84 & 1.34 \\
OR & 1.20 & 1.47 & 1.27 & 1.07 & 1.34 \\
OL & 0.69 & 0.82 & 1.78 & 1.19 & 0.35 \\
SNR & 0.45 & $1.69^{*}$ & 1.23 & 1.79 & 1.14 \\
SNL & 1.04 & 1.73 & 0.65 & 1.21 & 0.85 \\
SR & 1.63 & 0.84 & 0.58 & 0.81 & 1.67 \\
SL & 1.47 & 1.68 & 1.49 & 0.66 & 1.67 \\
\hline
\end{tabular}

Data are shown as median; FR—right frontal cortex, FL-left frontal cortex, HR—right hippocampus, HL-left hippocampus, OR - right olfactory bulb, OL-left olfactory bulb, SNR - right substantia nigra, SNL-left substantia nigra, SR-right striatum, SL-left striatum. * - data in the experimental group differ from data in the group of animals that received water $(\mathrm{p}<0.05)$. The levels of the transcripts studied in the control group (rats that received water) were set as 1.

ministration of SD: however, these changes were not significant. Relative levels of Gfral increased and Gfra2 decreased in the SNL compared with controls, but the level of Gdnf expression was not significantly different in this region of the brain. The level of Gfral transcript was increased in the SL compared with the controls. SD affected the expression of Gfra2 in the frontal cortex of both hemispheres, although in opposite directions; relative levels of the transcript were elevated in the FL and reduced in the FR 
Table 7. Relative levels of Gdnf and Gdnf receptor genes in various regions of the rat brain after SD administration.

\begin{tabular}{cccccc}
\hline & Gdnf & Gfral & Gfra2 & Gfra4 & Gfral \\
\hline FR & 0.79 & $0.73^{*}$ & $0.55^{*}$ & 0.92 & 0.90 \\
FL & 2.23 & 0.86 & $1.81^{*}$ & 1.10 & $1.95^{*}$ \\
HR & $3.05^{*}$ & 1.25 & 0.37 & 1.18 & 0.63 \\
HL & 1.06 & 1.01 & 1.09 & 0.79 & 1.29 \\
OR & $0.42^{*}$ & 0.76 & 1.26 & 1.09 & 0.83 \\
OL & 1.40 & 1.04 & 1.23 & 0.86 & 1.20 \\
SNR & $0.19^{*}$ & 1.65 & 1.86 & 0.84 & 0.79 \\
SNL & 1.51 & $2.11^{*}$ & $0.47^{*}$ & 1.63 & 1.20 \\
SR & $2.21^{*}$ & 1.42 & 1.27 & 0.56 & 1.94 \\
SL & 1.46 & $2.58^{*}$ & 1.79 & 0.63 & 1.77 \\
\hline
\end{tabular}

Data are shown as median; FR—right frontal cortex, FL-left frontal cortex, HR—right hippocampus, HL-left hippocampus, OR - right olfactory bulb, OL-left olfactory bulb, SNR - right substantia nigra, SNL-left substantia nigra, SR-right striatum, SL-left striatum. ${ }^{*}$ - data in the experimental group differ from data in the group of animals that received water $(\mathrm{p}<0.05)$. The levels of the transcripts studied in the control group (rats that received water) were set as 1 .

compared with the controls.

\section{Discussion}

In the present study, we investigated the effects of the synthetic peptides Semax, DNSP5 , and SD on the functioning of brain neurons. We conducted an analysis of motor activity, an analysis of the levels of DA, NA, 5-HT, and an expression analysis of Gdnf and Gdnf receptors Gfra1, Gfra2, Gfra4, and Gfral in various regions of the brain of rats with 6-OHDA-induced PD-like parkinsonism. Semax, DNSP-5, and SD affected the metabolism of DA in the rats with 6-OHDA-induced PD-like parkinsonism. The changes in the characteristics studied suggested that DNSP-5 and SD have neuroprotective properties. The administration of Semax did not appear to have any pronounced neuroprotective-like effects.

\subsection{Semax}

We did not find any changes in the motor activity or any alterations of the levels of DA in the striatum of the rats with 6-OHDA-induced induced PD-like parkinsonism after the administration of Semax. To our knowledge, there are no reports on how Semax affects the levels of DA, NA, 5-HT, or gene expression in 6-OHDA-induced models of PD. However, Semax has been shown to significantly reduce the number of damaged cells under conditions of oxidative stress caused by short-term incubation with hydrogen peroxide [37]. In addition, Semax has been shown to significantly increase the survival of cerebellar granule neurons during glutamate neurotoxicity, which may be mediated by its effect on calcium homeostasis and the functional state of mitochondria [38]. Clinical studies of the effect of Semax on the restoration of amnestic brain func- 
tion in patients with severe postresuscitational pathology (intellectual and mental disorders) showed that the majority of patients treated with Semax exhibited significant improvement [39]. Nevertheless, in the present study, Semax failed to show any neuroprotective effects, possibly because it might not affect the DA neurons, or because dose used was too small.

However, we did show that the level of 5-HT was significantly higher in the right striatum of rats that received Semax compared with the controls. The mechanisms underlying the effects of Semax on serotonergic systems are unknown. It could be assumed that Semax is able to modulate the serotonergic systems by affecting the melanocortinergic system. However, other neurotransmitter systems could be also involved. Semax may interact with dopaminergic autoreceptors in a manner similar to that of the ACTH-like peptides. Both the neurochemical and behavioral results indicate that Semax has modulating effects on striatal dopaminergic neurotransmission [40].

Semax did not affect the expression of most of the genes studied. To our knowledge, the effects of Semax on the expression of Gdnf and Gdnf receptors in PD have not been previously studied. Our data suggest that Semax does not have a neuroprotective effect in the 6-OHDA-induced model of PD, at least, not at the dose used in the present study. Taken together, our results do not support previous evidence of Semax's pronounced neuroprotective properties [41]-[43].

\subsection{DNSP-5}

DNSP-5 significantly elevated the level of DA in the SL. This may indicate that DNSP-5 increases DA synthesis in the surviving DA neurons. This effect is observed in the nonlesioned hemisphere, and although it may also occur in the lesioned hemisphere, the elevated DA level in the SR may be masked by reparative processes that occur in the few surviving DA neurons.

DNSP-5 is one of the predicted peptide products generated from post-translational processing of GDNF [44] [45]. The high conservation of DNSP-5 sequences among related species suggests its biological importance [4]. Littrell et al. showed an increase in the DA level in rats after a single DNSP-5 administration in the right striatum [4]. Our data are consistent with their results, despite the fact that we used course intranasal administration of the peptide instead of direct infusion into the brain. Our findings confirm that intranasal administration of the peptides can affect processes occurring in the brain [20].

DNSP-5 greatly affected the expression of the genes studied (Table 4). The most interesting results were for Gfral and Gfra2. Gfra1 and Gfra2 are the main Gdnf receptors, and DNSP-5 is a fragment of the Gdnf propeptide, which may have a regulatory function; therefore, our results suggest that DNSP-5 may intervene in the regulation of the Gdnf-receptor loop. However, Littrell et al. suggested otherwise [4]. DNSP-5 provided preservation of mitochondrial potentials and increased caspase-3 activation in dopaminergic cell lines. These cellular effects support a non-GDNF neuroprotective signaling mechanism [44]. 
Several studies have been conducted on Gfra1 function. Postsynaptic GFRA1 expression increases the preservation of striatal dopaminergic innervation [46]. Gfral may influence the viability and development of nigral DA neurons [47] [48]. GFRA1 may be necessary for GDNF to maintain normal function of the nigrostriatal dopaminergic system [49].

It is also likely that Gfra2 participates in the restoration of DA neurons. When stimulated with GDNF or NTN, both GFR $\alpha 2$ a and GFR $\alpha 2$, but not GFR $\alpha 2$ b, promoted neurite outgrowth [50] [51].

Thereby, an elevated level of DA in the SL and increased expression of Gfral and Gfra2 in the SL and SNR suggest compensatory and neuroprotective properties of DNSP-5. In general, our results indicate that DNSP-5 may increase the survival and restoration of DA neurons by stimulating Gfral and Gfra2 expression in the damaged $\mathrm{SN}$ and striatum.

DNSP-5 is most likely to negatively regulate the expression of $G d n f$ in the glial cells, because the mRNA levels of $G d n f$ were lower in the olfactory bulbs and SNR of rats that received DNSP-5 compared with control rats.

\subsection{SD}

Because SD is a relatively new peptide, to our knowledge, its effects on DA neurons have not been previously investigated.

In the present study, SD demonstrated similar, albeit less pronounced effects to DNSP-5 on DA metabolism and associated gene expression. It showed a tendency to increase the level of DA in the SL compared with controls. Unfortunately, the data were not significantly different, probably because of the small number of animals or because the dose of the peptide was too small. However, in conjunction with the data on motor activity in the "open field" test, our results suggest that SD has some neuroprotective properties or stimulates the surviving DA neurons.

SD affects gene expression in a manner resembling DNSP-5, especially in the $\mathrm{SN}$ and striatum. Although some differences were not significant, their similar effect could be explained by the cognate structure of the peptides.

GDNF expression is independently upregulated in the DA-depleted striatum [52][54]. In the present study, SD increased the levels of $G d n f$ mRNA in the SR more than water. Therefore, our data suggest that this peptide possesses neuroprotective properties similar to those of DNSP-5.

$\mathrm{SD}$ affected the expression of the genes studied in the FC and hippocampus of both hemispheres in a manner very similar to that of Semax. SD is probably hydrolyzed into fragments that are the same as most parts of Semax and DNSP-5. This would explain why the effects of SD resemble those of both Semax and DNSP-5.

\section{Conclusions}

We conducted a pilot study of the effects of the synthetic peptides Semax, DNSP-5, and $\mathrm{SD}$ in a 6-OHDA-induced rat model of PD. We showed that DNSP-5 and SD had po- 
tential neuroprotective properties. Because a very small proportion of the peptides reach the brain after intranasal administration, it is possible that larger doses may have more pronounced effects on DA metabolism, gene expression, and importantly, parkinsonism-like behavior.

Synthetic peptides are promising therapeutic agents, especially for treating neurodegenerative diseases. The results of our present study demonstrate that these peptides have great potential for PD treatment. However, further investigation is needed to evaluate DNSP-5 and SD as possible additions to current treatment for PD.

\section{Acknowledgements}

This work was supported by the Russian Foundation for Basic Research (project no. 15-34-20862), and the grant of Russian Scientific Foundation (Project no. 14-1501047).

\section{References}

[1] Bernheimer, H., Birkmayer, W., Hornykiewicz, O., Jellinger, K. and Seitelberger, F. (1973) Brain Dopamine and the Syndromes of Parkinson and Huntington. Clinical, Morphological and Neurochemical Correlations. Journal of the Neurological Sciences, 20, 415-455. http://dx.doi.org/10.1016/0022-510x(73)90175-5

[2] Cookson, M.R., Hardy, J. and Lewis, P.A. (2008) Genetic Neuropathology of Parkinson's Disease. International Journal of Clinical and Experimental Pathology, 1, 217-231.

[3] Michell, A.W., Lewis, S.J.G., Foltynie, T. and Barker, R.A. (2004) Biomarkers and Parkinson's disease. Brain, 127, 1693-1705. http://dx.doi.org/10.1093/brain/awh198

[4] Littrell, O.M., Fuqua, J.L., Richardson, A.D., Turchan-Cholewo, J., Hascup, E.R., Huettl, P., Pomerleau, F., Bradley, L.H., Gash, D.M. and Gerhardt, G.A. (2013) A Synthetic Five Amino Acid Propeptide Increases Dopamine Neuron Differentiation and Neurochemical Function. Neuropeptides, 47, 43-49. http://dx.doi.org/10.1016/j.npep.2012.08.004

[5] Muller, T. and Russ, H. (2006) Levodopa, Motor Fluctuations and Dyskinesia in Parkinson's Disease. Expert Opinion on Pharmacotherapy, 7, 1715-1730. http://dx.doi.org/10.1517/14656566.7.13.1715

[6] Salawu, F., Olokoba, A. and Danburam, A. (2010) Current Management of Parkinson's Disease. Annals of African Medicine, 9, 55-61. http://dx.doi.org/10.4103/1596-3519.64743

[7] Goudreau, J.L. (2006) Medical Management of Advanced Parkinson's Disease. Clinics in Geriatric Medicine, 22, 753-772. http://dx.doi.org/10.1016/j.cger.2006.06.006

[8] Airavaara, M., Voutilainen, M.H., Wang, Y. and Hoffer, B. (2012) Neurorestoration. Parkinsonism and Related Disorders, 18, S143-S146. http://dx.doi.org/10.1016/s1353-8020(11)70045-1

[9] Garea-Rodriguez, E., Eesmaa, A., Lindholm, P., Schlumbohm, C., Konig, J., Meller, B., Krieglstein, K., Helms, G., Saarma, M. and Fuchs, E. (2016) Comparative Analysis of the Effects of Neurotrophic Factors CDNF and GDNF in a Nonhuman Primate Model of Parkinson's Disease. PLoS ONE, 11, e0149776. http://dx.doi.org/10.1371/journal.pone.0149776

[10] Airaksinen, M.S. and Saarma, M. (2002) The GDNF Family: Signalling, Biological Functions and Therapeutic Value. Nature Reviews Neuroscience, 3, 383-394.

http://dx.doi.org/10.1038/nrn812

[11] Grondin, R. and Gash, D.M. (1998) Glial Cell Line-Derived Neurotrophic Factor (GDNF): 
A Drug Candidate for the Treatment of Parkinson's Disease. Journal of Neurology, 245, P35-P42. http://dx.doi.org/10.1007/PL00007744

[12] Hebert, M.A. and Gerhardt, G.A. (1997) Behavioral and Neurochemical Effects of Intranigral Administration of Glial Cell Line-Derived Neurotrophic Factor on Aged Fischer 344 Rats. Journal of Pharmacology and Experimental Therapeutics, 282, 760-768.

[13] Kearns, C.M., Cass, W.A., Smoot, K., Kryscio, R. and Gash, D.M. (1997) GDNF Protection against 6-OHDA: Time Dependence and Requirement for Protein Synthesis. The Journal of Neuroscience, 17, 7111-7118.

[14] Lin, L.F., Doherty, D.H., Lile, J.D., Bektesh, S. and Collins, F. (1993) GDNF: A Glial Cell Line-Derived Neurotrophic Factor for Midbrain Dopaminergic Neurons. Science, 260, 1130-1132. http://dx.doi.org/10.1126/science.8493557

[15] Lang, A.E., Gill, S., Patel, N.K., Lozano, A., Nutt, J.G., Penn, R., Brooks, D.J., Hotton, G., Moro, E., Heywood, P., et al. (2006) Randomized Controlled Trial of Intraputamenal Glial Cell Line-Derived Neurotrophic Factor Infusion in Parkinson Disease. Annals of Neurology, 59, 459-466. http://dx.doi.org/10.1002/ana.20737

[16] Salvatore, M.F., Zhang, J.L., Large, D.M., Wilson, P.E., Gash, C.R., Thomas, T.C., Haycock, J.W., Bing, G., Stanford, J.A., Gash, D.M. and Gerhardt, G.A. (2004) Striatal GDNF Administration Increases Tyrosine Hydroxylase Phosphorylation in the Rat Striatum and Substantia Nigra. Journal of Neurochemistry, 90, 245-254. http://dx.doi.org/10.1111/j.1471-4159.2004.02496.x

[17] Sherer, T.B., Fiske, B.K., Svendsen, C.N., Lang, A.E. and Langston, J.W. (2006) Crossroads in GDNF Therapy for Parkinson's Disease. Movement Disorders, 21, 136-141. http://dx.doi.org/10.1002/mds.20861

[18] Eslamboli, A. (2005) Assessment of GDNF in Primate Models of Parkinson's Disease: Comparison with Human Studies. Reviews in the Neurosciences, 16, 303-310. http://dx.doi.org/10.1515/REVNEURO.2005.16.4.303

[19] Kirik, D., Georgievska, B. and Bjorklund, A. (2004) Localized Striatal Delivery of GDNF as a Treatment for Parkinson Disease. Nature Neuroscience, 7, 105-110. http://dx.doi.org/10.1038/nn1175

[20] Aly, A.E. and Waszczak, B.L. (2015) Intranasal Gene Delivery for treating Parkinson's Disease: Overcoming the Blood-Brain Barrier. Expert Opinion on Drug Delivery, 12, $1923-$ 1941. http://dx.doi.org/10.1517/17425247.2015.1069815

[21] Kolomin, T., Shadrina, M., Slominsky, P., Limborska, S. and Myasoedov, N. (2013) A New Generation of Drugs: Synthetic Peptides Based on Natural Regulatory Peptides. Neuroscience \& Medicine, 223-252. http://dx.doi.org/10.4236/nm.2013.44035

[22] Ashmarin, I.P., Kamenskii, A.A. and Shelekhov, S.L. (1978) [Effect of a Fragment of Adrenocorticotropic Hormone $\left(\mathrm{ACTH}_{4-10}\right)$ on Learning in White Rats Given Positive Reinforcement]. Doklady Akademii Nauk SSSR, 240, 1245-1247.

[23] McGivern, R.F., Rose, G., Berka, C., Clancy, A.N., Sandman, C.A. and Beckwith, B.E. (1987) Neonatal Exposure to a High Level of $\mathrm{ACTH}_{4-10}$ Impairs Adult Learning Performance. Pharmacology Biochemistry \& Behavior, 27, 133-142. http://dx.doi.org/10.1016/0091-3057(87)90487-4

[24] Glebov, R.N. and Goriacheva, T.V. (1990) [ACTH as a Neuropeptide. The Functional Role of ACTH in the Brain]. Patologicheskaia Fiziologiia i EksperimentaP naia Terapiia, 54-57.

[25] Maurelli, M., Marchioni, E., Savoldi, F. and Tartara, A. (1987) Electroencephalographic, Behavioral and Autonomic Effects of Various ACTH Fragments in Rabbits. Farmaco, Edizione Scientifica, 42, 33-41. 
[26] Vwimersma Greidanus, T.B. and de Wied, D. (1971) Effects of Systemic and Intracerebral Administration of Two Opposite Acting ACTH-Related Peptides on Extinction of Conditioned Avoidance Behavior. Neuroendocrinology, 7, 291-301. http://dx.doi.org/10.1159/000121977

[27] Zager, E.L. and Black, P.M. (1985) Neuropeptides in Human Memory and Learning Processes. Neurosurgery, 17, 355-369. http://dx.doi.org/10.1227/00006123-198508000-00023

[28] Lois, J.F., Fischer, H.J., Mirra, J.M. and Gomes, A.S. (1986) Angiography of Histopathologic Variants of Synovial Sarcoma. Acta Radiologica: Diagnosis, 27, 449-454. http://dx.doi.org/10.1177/028418518602700416

[29] Azmitia, E.C. and de Kloet, E.R. (1987) ACTH Neuropeptide Stimulation of Serotonergic Neuronal Maturation in Tissue Culture: Modulation by Hippocampal Cells. Progress in Brain Research, 72, 311-318. http://dx.doi.org/10.1016/S0079-6123(08)60217-4

[30] Strand, F.L. and Kung, T.T. (1980) ACTH Accelerates Recovery of Neuromuscular Function Following Crushing of Peripheral Nerve. Peptides, 1, 135-138. http://dx.doi.org/10.1016/0196-9781(80)90077-7

[31] Gispen, W.H. and Zwiers, H. (1985) Behavioral and Neurochemical Effects of ACTH. In: Gispen, W.H., Ed., Neurochemistry, Springer-Verlag, New York, 375-412. http://dx.doi.org/10.1007/978-1-4684-7018-5_17

[32] Kelps, K.A., Turchan-Cholewo, J., Hascup, E.R., Taylor, T.L., Gash, D.M., Gerhardt, G.A. and Bradley, L.H. (2011) Evaluation of the Physical and in Vitro Protective Activity of Three Synthetic Peptides Derived from the Pro- and Mature GDNF Sequence. Neuropeptides, 45, 213-218. http://dx.doi.org/10.1016/j.npep.2011.03.003

[33] Suslov, O. and Steindler, D.A. (2005) PCR Inhibition by Reverse Transcriptase Leads to an Overestimation of Amplification Efficiency. Nucleic Acids Research, 33, e181. http://dx.doi.org/10.1093/nar/gni176

[34] Gruden, M.A., Davydova, T.V., Narkevich, V.B., Fomina, V.G., Wang, C., Kudrin, V.S., Morozova-Roche, L.A. and Sewell, R.D. (2015) Noradrenergic and Serotonergic Neurochemistry Arising from Intranasal Inoculation with Alpha-Synuclein Aggregates which Incite Parkinsonian-Like Symptoms. Behavioural Brain Research, 279, 191-201. http://dx.doi.org/10.1016/j.bbr.2014.11.001

[35] Gruden, M.A., Davydova, T.V., Narkevich, V.B., Fomina, V.G., Wang, C., Kudrin, V.S., Morozova-Roche, L.A. and Sewell, R.D. (2014) Intranasal Administration of alpha-Synuclein Aggregates: A Parkinson's Disease Model with Behavioral and Neurochemical Correlates. Behavioural Brain Research, 263, 158-168. http://dx.doi.org/10.1016/j.bbr.2014.01.017

[36] Livak, K.J. and Schmittgen, T.D. (2001) Analysis of Relative Gene Expression Data Using Real-Time Quantitative PCR and the $2^{-\Delta \Delta C T}$ Method. Methods, 25, 402-408. http://dx.doi.org/10.1006/meth.2001.1262

[37] Safarova, E.R., Shram, S.I., Zolotarev, Y.A. and Myasoedov, N.F. (2003) Effect of Semax Peptide on Survival of Cultured Rat Pheochromocytoma Cells during Oxidative Stress. Bulletin of Experimental Biology and Medicine, 135, 268-271. http://dx.doi.org/10.1023/A:1024141232307

[38] Storozhevykh, T.P., Tukhbatova, G.R., Senilova, Y.E., Pinelis, V.G., Andreeva, L.A. and Myasoyedov, N.F. (2007) Effects of Semax and Its Pro-Gly-Pro Fragment on Calcium Homeostasis of Neurons and Their Survival under Conditions of Glutamate Toxicity. Bulletin of Experimental Biology and Medicine, 143, 601-604. http://dx.doi.org/10.1007/s10517-007-0192-x 
[39] Alekseeva, G.V., Bottaev, N.A. and Goroshkova, V.V. (1999) [Use of Semax at a Follow-Up of Patients with Posthypoxic Encephalopathy]. Anesteziologiia i Reanimatologiia, 1, 40-43.

[40] Eremin, K.O., Kudrin, V.S., Saransaari, P., Oja, S.S., Grivennikov, I.A., Myasoedov, N.F. and Rayevsky, K.S. (2005) Semax, an $\mathrm{ACTH}_{4-10}$ Analogue with Nootropic Properties, Activates Dopaminergic and Serotoninergic Brain Systems in Rodents. Neurochemical Research, 30, 1493-1500. http://dx.doi.org/10.1007/s11064-005-8826-8

[41] Grivennikov, I.A., Dolotov, O.V. and Gol'dinaIu, I. (1999) [Peptide Factors in Processes of Proliferation, Differentiation, and Extended Viability of Mammalian Nervous System Cells]. Molecular Biology, 33, 120-126.

[42] Grivennikov, I.A., Dolotov, O.V., Zolotarev, Y.A., Andreeva, L.A., Myasoedov, N.F., Leacher, L., Black, I.B. and Dreyfus, C.F. (2008) Effects of Behaviorally Active $\mathrm{ACTH}_{4-10}$ Analogue-Semax on Rat Basal Forebrain Cholinergic Neurons. Restorative Neurology and Neuroscience, 26, 35-43.

[43] Romanova, G.A., Silachev, D.N., Shakova, F.M., Kvashennikova, Y.N., Viktorov, I.V., Shram, S.I. and Myasoedov, N.F. (2006) Neuroprotective and Antiamnesic Effects of Semax during Experimental Ischemic Infarction of the Cerebral Cortex. Bulletin of Experimental Biology and Medicine, 142, 663-666. http://dx.doi.org/10.1007/s10517-006-0445-0

[44] Bradley, L.H., Fuqua, J., Richardson, A., Turchan-Cholewo, J., Ai, Y., Kelps, K.A., Glass, J.D., He, X., Zhang, Z., Grondin, R., et al. (2010) Dopamine Neuron Stimulating Actions of a GDNF Propeptide. PLOS ONE, 5, e9752. http://dx.doi.org/10.1371/journal.pone.0009752

[45] Immonen, T., Alakuijala, A., Hytonen, M., Sainio, K., Poteryaev, D., Saarma, M., Pasternack, M. and Sariola, H. (2008) A proGDNF-Related Peptide BEP Increases Synaptic Excitation in Rat Hippocampus. Experimental Neurology, 210, 793-796. http://dx.doi.org/10.1016/j.expneurol.2007.12.018

[46] Kholodilov, N., Kim, S.R., Yarygina, O., Kareva, T., Cho, J.W., Baohan, A. and Burke, R.E. (2011) Glial Cell Line-Derived Neurotrophic Factor Receptor-Alpha1 Expressed in Striatum in Trans Regulates Development and Injury Response of Dopamine Neurons of the Substantia Nigra. Journal of Neurochemistry, 116, 486-498.

http://dx.doi.org/10.1111/j.1471-4159.2010.07128.x

[47] Cho, J., Yarygina, O., Oo, T.F., Kholodilov, N.G. and Burke, R.E. (2004) Glial Cell Line-Derived Neurotrophic Factor Receptor GFRalpha1 Is Expressed in the Rat Striatum during Postnatal Development. Molecular Brain Research, 127, 96-104. http://dx.doi.org/10.1016/j.molbrainres.2004.05.015

[48] Boger, H.A., Middaugh, L.D., Zaman, V., Hoffer, B. and Granholm, A.C. (2008) Differential Effects of the Dopamine Neurotoxin MPTP in Animals with a Partial Deletion of the GDNF Receptor, GFR alpha1, Gene. Brain Research, 1241, 18-28. http://dx.doi.org/10.1016/j.brainres.2008.09.011

[49] Zaman, V., Boger, H.A., Granholm, A.C., Rohrer, B., Moore, A., Buhusi, M., Gerhardt, G.A., Hoffer, B.J. and Middaugh, L.D. (2008) The Nigrostriatal Dopamine System of Aging GFRalpha-1 Heterozygous Mice: Neurochemistry, Morphology and Behavior. European Journal of Neuroscience, 28, 1557-1568. http://dx.doi.org/10.1111/j.1460-9568.2008.06456.x

[50] Yoong, L.F. and Too, H.P. (2007) Glial Cell Line-Derived Neurotrophic Factor and Neurturin Inhibit Neurite Outgrowth and Activate RhoA through GFR alpha 2b, an Alternatively Spliced Isoform of GFR Alpha 2. Journal of Neuroscience, 27, 5603-5614. http://dx.doi.org/10.1523/JNEUROSCI.4552-06.2007

[51] Wan, G., Zhou, L., Lim, Q., Wong, Y.H. and Too, H.P. (2011) Cyclic AMP Signalling through PKA but Not Epac Is Essential for Neurturin-Induced Biphasic ERK1/2 Activation and Neurite Outgrowths through GFRalpha2 Isoforms. Cellular Signalling, 23, 1727-1737. 
http://dx.doi.org/10.1016/j.cellsig.2011.06.007

[52] Zhou, J., Yu, Y., Tang, Z., Shen, Y. and Xu, L. (2000) Differential Expression of mRNAs of GDNF Family in the Striatum Following 6-OHDA-Induced Lesion. NeuroReport, 11, 32893293. http://dx.doi.org/10.1097/00001756-200009280-00048

[53] Nakagawa, T. and Schwartz, J.P. (2004) Gene Expression Profiles of Reactive Astrocytes in Dopamine-Depleted Striatum. Brain Pathology, 14, 275-280. http://dx.doi.org/10.1111/j.1750-3639.2004.tb00064.x

[54] Nakajima, K., Hida, H., Shimano, Y., Fujimoto, I., Hashitani, T., Kumazaki, M., Sakurai, T. and Nishino, H. (2001) GDNF Is a Major Component of Trophic Activity in DA-Depleted Striatum for Survival and Neurite Extension of DAergic Neurons. Brain Research, 916, 7684. http://dx.doi.org/10.1016/S0006-8993(01)02866-9

\section{Submit or recommend next manuscript to SCIRP and we will provide best service} for you:

Accepting pre-submission inquiries through Email, Facebook, LinkedIn, Twitter, etc.

A wide selection of journals (inclusive of 9 subjects, more than 200 journals)

Providing 24-hour high-quality service

User-friendly online submission system

Fair and swift peer-review system

Efficient typesetting and proofreading procedure

Display of the result of downloads and visits, as well as the number of cited articles

Maximum dissemination of your research work

Submit your manuscript at: http://papersubmission.scirp.org/

Or contactwjns@scirp.org 